\title{
Protective Effect of a 21-Aminosteroid during Experimental Pneumococcal Meningitis
}

\author{
Stefan Lorenzl, Uwe Koedel, Karl Frei, \\ Andrea Bernatowicz, Adriano Fontana, \\ and Hans-Walter Pfister
}

\author{
Department of Neurology, Klinikum Großhadern, Ludwig-Maximilians- \\ University of Munich, Germany; Section of Clinical Immunology, \\ University Hospital, Zurich, Switzerland
}

\begin{abstract}
This study investigated whether the 21-aminosteroid U74389F, an inhibitor of lipid peroxidation, attenuates pathophysiologic changes in experimental pneumococcal meningitis. Infected rats injected intravenously with vehicle and $\mathrm{U} 74389 \mathrm{~F}$ developed increases in regional cerebral blood flow ( $\mathrm{rCBF}$ ), intracranial pressure (ICP), brain water content, and white blood cells (WBC) in cerebrospinal fluid (CSF) within $8 \mathrm{~h}$ after intracisternal challenge. Pretreatment with or administration of U74389F $4 \mathrm{~h}$ after infection significantly reduced the increase in ICP but had no effect on rCBF increase. Moreover, U74389F pretreatment significantly reduced brain water content and CSF WBC count. In vitro, U74389F inhibited iron-dependent lipid peroxidation of astrocyte cultures and the production of tumor necrosis factor- $\alpha$, interleukin-6, and nitric oxide by stimulated macrophages. These data suggest that U74389F modulates early pathophysiologic alterations in experimental pneumococcal meningitis.
\end{abstract}

Animal models of bacterial meningitis have increased our knowledge of the complex pathophysiologic mechanisms of the disease [1-5]. In a rat model of meningitis, we showed that intracisternal (ic) inoculation of live pneumococci or pneumococcal cell wall components induces an early increase in regional cerebral blood flow (rCBF), intracranial pressure (ICP), and brain water content [6]. Pretreatment with free superoxide dismutase (SOD), polyethylene glycol (PEG)-conjugated SOD, deferoxamine, and catalase greatly attenuates these pathophysiologic changes; the strongest effects are shown with SOD and PEG-SOD [6-8]. Findings by other investigators support a role for reactive oxygen species in the pathophysiology of bacterial meningitis $[9,10]$. Cellular injury caused by reactive oxygen species may involve direct damage to proteins and DNA as well as lipid peroxidation [11]. Here we tested the effect of the novel 21-aminosteroid U74389F [12, 13], an inhibitor of lipid peroxidation, for its capacity to alter rCBF, ICP, and brain edema formation and to reduce meningeal inflammation in experimental pneumococcal meningitis.

\section{Materials and Methods}

Animal preparation. We used a well-characterized rat meningitis model that has been described in detail [6]. Adult male Wistar rats $(250-330 \mathrm{~g})$ were intraperitoneally anesthetized with $100 \mathrm{mg} /$

Received 8 February 1994; revised 13 December 1994.

Presented in part: 33rd Interscience Conference on Antimicrobial Agents and Chemotherapy, New Orleans, 17-20 October 1993 (abstract 793).

Financial support: Deutsche Forschungsgemeinschaft (Pf 246/3-2).

Reprints of correspondence: Dr. Hans-Walter Pfister, Dept. of Neurology, Klinikum Grosshadern, Marchioninistrasse 15, 81377 Munich, Germany.

The Journal of Infectious Diseases 1995; 172:113-8

1995 by The University of Chicago. All rights reserved

$0022-1899 / 95 / 7201-0015 \$ 01.00$ kg thiobutabarbiturate (Inactin; Byk Gulden, Konstanz, Germany), tracheotomized, and artificially ventilated (small animal ventilator, model 683; Harvard, South Natick, MA). End-expiratory $\mathrm{CO}_{2}$ was continuously monitored by infrared $\mathrm{CO}_{2}$ analyzer (model 2200; Heyer, Bad Ems, Germany). Mean arterial blood pressure (MABP) was measured by pressure transducer (Statham P23; Viggo-Spectramed, Oxnard, CA) connected to the femoral artery cannula. Arterial blood gases and hematocrit were determined before ic inoculation and every $2 \mathrm{~h}$ thereafter (gas check model 1304; Instrumentation Laboratory, Kirchheim, Germany). Body temperature was maintained at $38^{\circ} \mathrm{C}$ by a rectal thermometer-controlled heating pad. Rats were placed in a stereotaxic frame, and a burr hole was made in the occipital bone for placement of the cisterna magna catheter. A 5-mm-diameter craniotomy was made in the right parietal bone for the placement of a laser-Doppler probe. rCBF was measured continuously by laser-Doppler flowmetry (model BPM 403a; Vasamedics, St. Paul, MN). Changes in rCBF were expressed as percent changes from baseline. The dura was left intact in all preparations.

Cerebrospinal fluid (CSF; $100 \mu \mathrm{L}$ ) was withdrawn through the cisterna magna catheter, and meningitis was induced by ic injection of $100 \mu \mathrm{L}$ of pneumococci $\left(\approx 10^{6} \mathrm{cfu}\right.$ ). We used Streptococcus pneumoniae type 3 (no. 17260), an isolate from an endotracheal aspiration of a patient with septic infection that was maintained at $-20^{\circ} \mathrm{C}$ in trypticase soy broth (Oxoid, Wesel, Germany) supplemented with $10 \%$ glyccrol and $1 \%$ IsoVitale (Becton Dickinson Microbiology Systems, Heidelberg, Germany). Before use, the bacteria were subcultured on blood-agar plates, checked for purity, inoculated into brain-heart infusion broth (Oxoid), supplemented with $3 \%$ horse serum and $1 \%$ bovine albumin (Serva, Heidelberg, Germany), and incubated overnight at $35^{\circ} \mathrm{C}$. The broth was centrifuged for $20 \mathrm{~min}$ at $2500 \mathrm{~g}$, and the sediment was washed once with $0.85 \%$ saline and resuspended in saline. The final suspension was turbidimetrically adjusted to an optical density of 0.5 at 546 nm (photometer with 13-mm filter; Eppendorf, Hamburg, Germany), thus achieving a concentration of $\approx 10^{7} \mathrm{cfu} / \mathrm{mI}$.

The following parameters were continuously monitored for $8 \mathrm{~h}$ after ic injection by a personal computer system after analog- 
digital conversion for signal processing: ICP (measured by Statham P23 pressurc transducer connected to the cisterna magna catheter), rCBF, and MABP. Blood and CSF white blood cell (WBC) counts were determined at bascline and 4 and $8 \mathrm{~h}$ after ic injection. At the end of the experiment, the reactivity of the cerebral circulation to $\mathrm{CO}_{2}$ was tested. Hypercapnia was produced with $10 \% \mathrm{CO}_{2}$, $21 \% \mathrm{O}_{2}$, and the balance of $\mathrm{N}_{2}$. Before and $10 \mathrm{~min}$ after hypercapnia, arterial blood samples were drawn for blood gas and pH analysis. To determine brain water content, brains werc weighed in glass dishes then dried for $16 \mathrm{~h}$ at $130^{\circ} \mathrm{C}$ to stable weight. Brain water content was calculated by the formula [(wet weight - dry weight $) /$ wet weight $] \times 100[6]$.

We studied 6 groups of rats: There were 6 infected rats in groups $1-3,6$ uninfected animals in group 4, and 3 and 4 infected rats in groups 5 and 6 , respectively. Animals in group 1 were injected intravenously (iv) with vehicle of U74389F: 21-[4-(2,6-di-1-pyrrolidinyl-4-pyrimidinyl)-1-piperazinyl]-pregna-1,4,9 (11)-triene3,20-dione, monomethansulfonate (provided by Upjohn, Kalama-

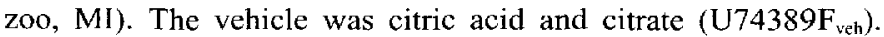
Group 2 animals were treated iv with U74389F $15 \mathrm{~min}$ before ( 3 $\mathrm{mg} / \mathrm{kg})$ and $2 \mathrm{~h}$ after $(1.5 \mathrm{mg} / \mathrm{kg})$ ic pneumococcal challenge. Rats in group 3 were treated iv with U74389F $4 \mathrm{~h}$ after $(3 \mathrm{mg} / \mathrm{kg})$ and $6 \mathrm{~h}$ after $(1.5 \mathrm{mg} / \mathrm{kg})$ ic infection. Group 4 rats were injected iv with U74389F $15 \mathrm{~min}$ before $(3 \mathrm{mg} / \mathrm{kg})$ and $2 \mathrm{~h}$ after $(1.5 \mathrm{mg} / \mathrm{kg})$ ic injection of PBS. Rats in group 5 were treated iv with $\mathrm{U} 74389 \mathrm{~F}$ $15 \mathrm{~min}$ before $(30 \mathrm{mg} / \mathrm{kg})$ and $2 \mathrm{~h}$ after $(15 \mathrm{mg} / \mathrm{kg})$ ic infection (5-h measurement period). Group 6 rats were pretreated iv with U 74389F $15 \mathrm{~min}$ before $(3 \mathrm{mg} / \mathrm{kg})$ and $2 \mathrm{~h}$ after $(1.5 \mathrm{mg} / \mathrm{kg})$ ic infection, the NO synthase inhibitor N-nitro-L-arginine (L-NA; 10 $\mathrm{mg} / \mathrm{kg}$ ) was administered iv $4 \mathrm{~h}$ after ic infection (5-h measurement period).

In vitro experiments. We investigated whether $\mathrm{U} 74389 \mathrm{~F}$ is a potent inhibitor of lipid peroxidation when central nervous system (CNS) cells are used. For this purpose, primary rat astrocytes were stimulated with heat-killed pneumococci; lipid peroxidation was assessed by the formation of thiobarbituric acid-reactive products. The data were compared with those of methylprednisolone, a known potent inhibitor of lipid peroxidation.

For initiation of lipid peroxidation, primary rat astrocytes were incubated with $200 \mu M \mathrm{Fe}^{3+}$ and $50 \mu M \mathrm{Fe}^{2+}$ in $0.9 \%$ saline for $0.5 \mathrm{~h}$ at $37^{\circ} \mathrm{C}[14] . \mathrm{Fe}^{3+}$ and $\mathrm{Fe}^{2+}$ solutions (Aldrich Chemie, Steinheim, Germany) were prepared fresh in argon-purged $\mathrm{H}_{2} \mathrm{O}$ and used immediately. Astrocytes and the supernatant were removed, homogenized, and sonicated for $30 \mathrm{~s}$. After centrifugation $\left(800 \mathrm{~g}, 5 \mathrm{~min}, 4^{\circ} \mathrm{C}\right), 150 \mu \mathrm{L}$ of the cell suspension was incubated with $1 \mathrm{~mL}$ of $0.5 \%$ thiobarbituric acid (Aldrich Chemic, Steinheim, Germany) in $12.5 \%$ trichloracetic acid (Aldrich Chemie) for 10 min at $90^{\circ} \mathrm{C}$. After samples were centrifuged $(800 \mathrm{~g}, 5 \mathrm{~min}$, room temperature), the formation of thiobarbituric acid-reactive oxidation products was determined at $A_{532}$ (Ultrospec III; Pharmacia LKB, Freiburg, Germany). Quantification was based upon a molar extinction coefficient of $1.56 \times 10^{5}$ [14]. The following groups were investigated: addition of U74389F $\mathrm{Feh}_{\mathrm{ve}}(n=16)$; U74389F, $100 \mu M(n=6)$ and $1 \mathrm{~m} M(n=6), 10 \mathrm{mM}(n=4)$; methylprednisolone vehicle $(n=6)$; methylprednisolone, $1 \mathrm{~m} M(n=6)$ and $10 \mathrm{mM}(n=4)$; controls ( $n=6$; addition of the diluent of $\mathrm{Fe}^{2+}$ ) $\mathrm{Fe}^{3+}$ plus $\left.\mathrm{U} 74389 \mathrm{~F}_{\mathrm{vel}}\right)$.

Primary astrocyte cultures were prepared from the cerebral cortex of 1-day-old neonatal Wistar rats and grown on 6-well plates
(Falcon; Becton Dickinson, Plymouth, UK) at $37^{\circ} \mathrm{C}$ in a $5 \% \mathrm{CO}_{2}$ incubator with $95 \%$ oxygen. During the first 7 days, the astrocytes were maintained in Dulbecco's modified Eagle medium (DMEM) supplemented with $20 \%$ heat-inactivated fetal calf serum (FCS). On day 8 , the medium was replaced and the astrocytes were maintained in DMEM plus 5\% FCS. Astrocytes were cultivated in 6well plates in culture medium until confluence. When confluence was documented (days 12-14), the astrocytes were shaken at 400 rpm for $3 \mathrm{~h}$ to remove microglia and oligodendrocytes. Astrocytes were then maintained 1 day in G5 medium [15] to eliminate microglia and oligodendrocytes. Astrocyte cultures were characterized on the basis of morphologic criteria and by the expression of glial fibrillary acidic protein (GFAP) as detected by immunostaining. These primary astrocyte cultures consisted of $>95 \%$ GFAPpositive cells. We used only astrocytes without any passage. Before stimulation, astrocytes were washed with PBS without $\mathrm{Ca}^{2+}$ and $\mathrm{Mg}^{2+}$ and maintained in DMEM with $5 \%$ FCS without phenol red and antibiotics.

Peritoneal macrophage cultures. We also questioned whether the activity of $U 74389 \mathrm{~F}$ was restricted to inhibition of lipid peroxidation. Thus, we tested to see if it interfered with the production of known mediators of bacterial meningitis, such as cytokines and NO. Peritoneal macrophages were stimulated with heat-killed pneumococci, lipopolysaccharide (LPS), and cytokines. Peritoneal exudate cells were obtained from 8 -week-old female Wistar rats that were injected intraperitoneally with $6 \mathrm{~mL}$ of Brewer's thioglycollate medium 3 days before isolation. The cells were cultured in DMEM (Biochrom, Berlin) supplemented with 1\% FCS (Biochrom), $10 \mu \mathrm{g} / \mathrm{mL}$ gentamicin, and $1 \mathrm{mM} \mathrm{N}$-acetyl-L-alanyl-Lglutamine. Cells were stimulated with heat-killed $\left(60^{\circ} \mathrm{C}, 4 \mathrm{~h}\right)$ unencapsulated pneumococci (HKP; isogenic mutant of $S$. pneumoniae type 3 , no. 17260) in three different concentrations $\left(10^{5}, 10^{6}\right.$, and $10^{7} \mathrm{cfu} / \mathrm{mL}$ ), LPS (Escherichia coli $0127: \mathrm{B} 8 ; 1 \mu \mathrm{g} / \mathrm{mL}$ ) or murine recombinant interferon- $\gamma(\mathrm{rIFN}-\gamma ; 100 \mathrm{U} / \mathrm{mL})$ plus murine recombinant tumor necrosis factor- $\alpha$ (rTNF $-\alpha ; 10 \mathrm{ng} / \mathrm{mL}$ ). Murine rTNF$\alpha$ and rIFN- $\gamma$ were both purchased from Boehringer (Mannheim, Germany). E. coli LPS was obtained from Difco (Detroit). Cell cultures were untreated or treated with $\mathrm{U} 74389 \mathrm{~F}(1,10$, or 100 $\mu M$ ) or $U 74389 \mathrm{~F}_{\text {veh. }}$. Interleukin (IL) 6 and TNF $\alpha$ were measured using 7TDl cells [16] and L-M cells [17], respectively. NO production in the cell culture supernatant was assessed by measuring nitrite, a stable metabolic product of NO, by the Griess reaction [18].

Statistical methods. Data on rCBF, ICP, and CSF WBC count obtained 4 and $8 \mathrm{~h}$ after ic pneumococcal challenge in rats injected iv with $U 74389 \mathrm{~F}_{\text {veh }}$ or $\mathrm{U} 74389 \mathrm{~F}$ (groups 1 and 2) were compared by unpaired Student's $t$ test; $P$ values were corrected for repeated measurements using the Bonferroni-Holm procedure. Data on brain water content and $\mathrm{CO}_{2}$ reactivity at $8 \mathrm{~h}$ after ic challenge from groups 1 and 2 were compared by the unpaired Student's $t$ test. Data on rCBF, ICP, and CSF WBC count at $4 \mathrm{~h}$ after ic challenge in infected rats injected iv with $\mathrm{U} 74389 \mathrm{~F}$ in two different dosages (groups 2 and 5) were compared by unpaired Student's $t$ test. Data on $\mathrm{rCBF}, \mathrm{ICP}$, and CSF WBC count at 4 and $5 \mathrm{~h}$ after ic challenge in infected rats injected iv with $\mathrm{U} 74389 \mathrm{~F}$ or with U74389F plus L-NA (groups 2 and 6) were compared by unpaired Student's $t$ test; $P$ values were corrected for repeated measurements using the Bonferroni-Holm procedure. One-way analysis of variance and Student-Newman-Keuls multiple comparisons were used 
Table 1. Pathophysiologic parameters in different experimental groups of rats.

\begin{tabular}{|c|c|c|c|c|c|c|c|c|}
\hline \multirow[b]{2}{*}{ Group } & \multicolumn{2}{|c|}{$\begin{array}{c}\text { Regional cerebral blood } \\
\text { flow }(\%)\end{array}$} & \multicolumn{2}{|c|}{$\begin{array}{l}\text { Intracranial pressure } \\
(\mathrm{mm} \mathrm{Hg})\end{array}$} & \multicolumn{2}{|c|}{$\begin{array}{l}\text { CSF white blood cell count } \\
\text { (cells } / \mu \mathrm{L})\end{array}$} & \multirow{2}{*}{$\begin{array}{c}\text { Brain water } \\
\text { content }(\%) \\
\text { at } 8 \mathrm{~h}\end{array}$} & \multirow{2}{*}{$\begin{array}{l}\mathrm{CO}_{2} \\
\text { reactivity* } \\
\text { at } 8 \mathrm{~h}\end{array}$} \\
\hline & $4 \mathrm{~h}$ & $8 \mathrm{~h}$ & $4 \mathrm{~h}$ & $8 \mathrm{~h}$ & $4 \mathrm{~h}$ & $8 \mathrm{~h}$ & & \\
\hline \multicolumn{9}{|l|}{ Infected } \\
\hline $\mathrm{U} 74389 \mathrm{~F}_{\mathrm{veh}}$ injected & $175.3 \pm 7.0$ & $211.6 \pm 5.2$ & $13.3 \pm 1.7$ & $15.4 \pm 1.2$ & $2611 \pm 551$ & $6710 \pm 729$ & $79.09 \pm 0.03$ & $1.38 \pm 0.56$ \\
\hline U74389F pretreated & $151.8 \pm 7.0$ & $204.4 \pm 3.1$ & $9.0 \pm 1.4$ & $11.0 \pm 1.0^{\dagger}$ & $1095 \pm 163^{\dagger}$ & $4297 \pm 289^{\dagger}$ & $78.80 \pm 0.06^{\dagger}$ & $0.86 \pm 0.26$ \\
\hline Uninfected, U74389F injected & $107.9 \pm 5.6$ & $115.6 \pm 6.5$ & $2.1 \pm 0.3$ & $3.8 \pm 0.9$ & $6 \pm 2$ & $23 \pm 10$ & $77.91 \pm 0.10$ & $1.34 \pm 0.45$ \\
\hline
\end{tabular}

NOTE. Each group, $n=6$.

* Change in regional cerebral blood flow $(\%) /$ change in $\mathrm{PCO}_{2}(\mathrm{~mm} \mathrm{IIg})$.

${ }^{i} P<.05$, vs. infected, $\mathrm{U} 74389 \mathrm{~F}_{\mathrm{vch}}$-injected rats.

to compare data on thiobarbituric acid reactive products. Differences were considered significant when $P<.05$. Data are expressed as mean $\pm \mathrm{SE}$.

\section{Results}

Physiologic variables. $\mathrm{MABP}, \mathrm{PO}_{2}, \mathrm{PCO}_{2}, \mathrm{pH}$, hematocrit, and body temperature were normal throughout the experiment in all groups (data not shown). Cerebrovascular $\mathrm{CO}_{2}$ reactivity did not differ significantly between groups (table 1).

rCBF, ICP, brain water content, and CSF WBC count. There was an increase in rCBF in $U 74389 \mathrm{~F}_{\mathrm{veh}}$-injected infected rats (group 1) from a baseline of $100 \%$ to $211.6 \% \pm 5.2 \%$ within $8 \mathrm{~h}$ after pneumococcal challenge (table 1; figure 1). In infected rats pretreated with U74389F (group 2), the mean values of rCBF at 4 and $8 \mathrm{~h}$ after ic injection did not differ significantly from that of infected rats pretreated with $\mathrm{U} 74389 \mathrm{~F}_{\text {veh }}$ (table 1).

ICP markedly increased in infected $U 74389 \mathrm{~F}_{\text {veh }}$-injected rats (group 1) within $8 \mathrm{~h}$ after infection from a baseline of $3.6 \pm$ $0.4 \mathrm{~mm} \mathrm{Hg}$ to $15.4 \pm 1.2 \mathrm{~mm} \mathrm{Hg}$ (figure 1, table 1). Pretreatment with U74389F (group 2) significantly attenuated the increase in ICP at $8 \mathrm{~h}$ (table 1). There was no change in rCBF and ICP in uninfected rats pretreated with $\mathrm{U} 74389 \mathrm{~F}$ and injected ic with PBS (group 4; table 1). Pretreatment with U74389F (group 2) significantly reduced brain water content and CSF WBC counts $(P<.05$; table 1$)$.

The inhibitory effect of U74389F (group 2) on ICP and CSF pleocytosis in infected rats was not enhanced when infected rats were pretreated with the higher dosage of U74389F (group 5). For example, at $4 \mathrm{~h}$ after infection, ICP was $10.7 \pm 4.2$ $\mathrm{mm} \mathrm{Hg}$ in group 5 versus $11.0 \pm 1.0 \mathrm{~mm} \mathrm{Hg}$ in group 2, and CSF WBC count was $1021 \pm 305$ versus $1095 \pm 163$ cells/ $\mu \mathrm{L}$. There was also no effect on $\mathrm{rCBF}(171.1 \% \pm 26.0 \% \mathrm{vs}$. $151.8 \% \pm 7.0 \%$ at $4 \mathrm{~h}$ after infection).

Compared with effects observed in $\mathrm{U} 74389 \mathrm{~F}_{\mathrm{veh}}$-injected rats (group 1), the administration of U74389F $4 \mathrm{~h}$ after ic infection (group 3) significantly attenuated the increase in ICP (7.6 \pm 1.5 vs. $15.4 \pm 1.2 \mathrm{~mm} \mathrm{Hg}$, groups 3 and 1 , respectively) but
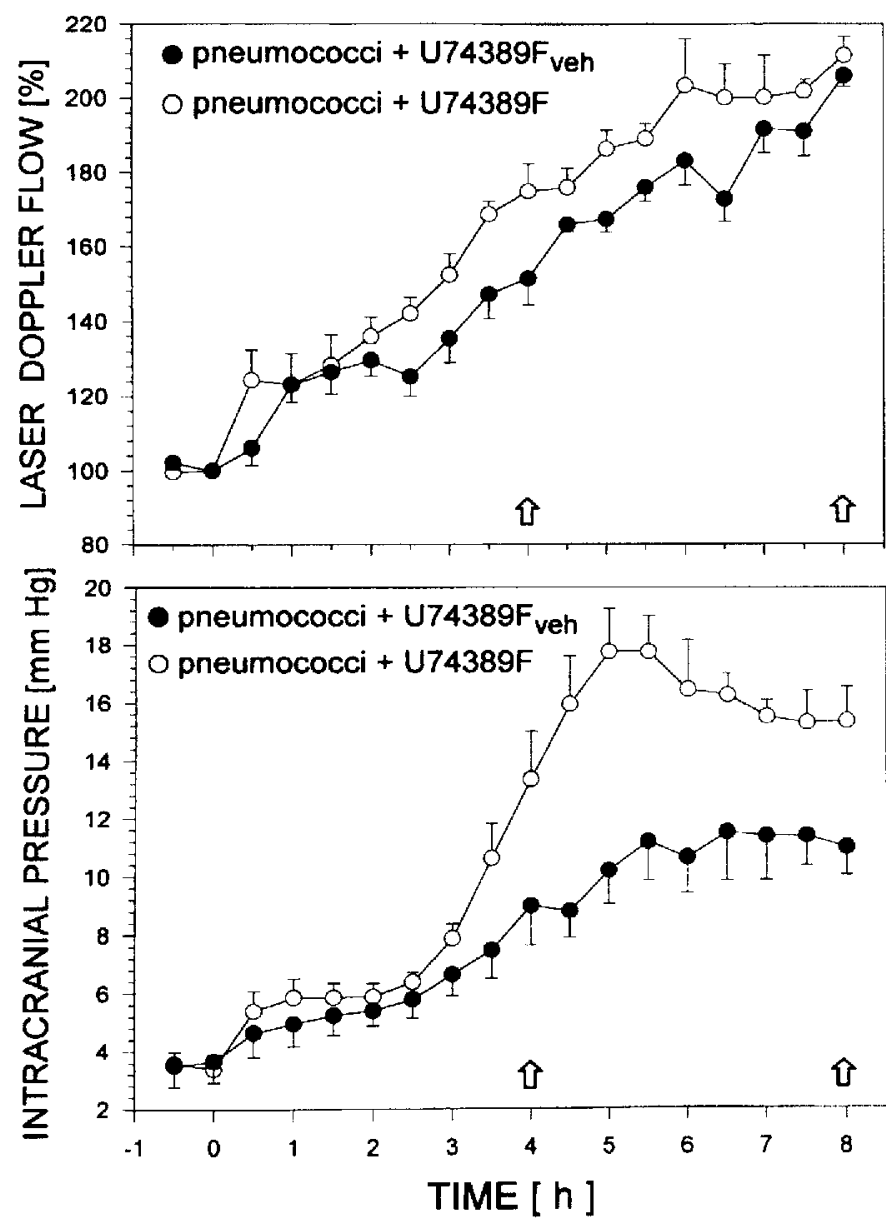

Figure 1. Time course of regional cerebral blood flow (rCBF) and intracranial pressure (ICP) in infected rats injected with $\mathrm{U} 74389 \mathrm{~F}$ or its vehicle $\left(\mathrm{U}^{7} 4389 \mathrm{~F}_{\mathrm{veh}}\right.$ ) before infection. $\mathrm{rCBF}$ and ICP increased in both groups. Statistical analysis was done 4 and $8 \mathrm{~h}$ after intracisternal injection (arrows) by unpaired Student's $t$ test. $P$ values were corrected for repeated measurements by Bonferroni-Holm procedure. Pretreatment with U74389F significantly reduced increase in ICP $8 \mathrm{~h}$ after infection (see table 1). Data are mean $\pm \mathrm{SE}$. 
Table 2. Effect of different doses of U74389F on the production of nitric oxide, interleukin-6 (IL-6), and tumor necrosis factor- $\alpha$ (TNF- $\alpha$ ) by rat peritoneal macrophages.

\begin{tabular}{|c|c|c|c|}
\hline Group & $\mathrm{NO}_{2}^{-}(\mu M)$ & IL-6 (U/mL) & TNF- $\alpha^{*}(\mathrm{U} / \mathrm{mL})$ \\
\hline $\mathrm{U} 74389 \mathrm{~F}_{\mathrm{veb}}$ & 78.2 & 1500 & $<5$ \\
\hline$+\mathrm{U} 74389 \mathrm{~F}, 10 \mu \mathrm{M}$ & 68.3 & 800 & $<5$ \\
\hline HKP & 92.5 & 72,960 & 85 \\
\hline$+\mathrm{U} 74389 \mathrm{~F}, 1 \mu M$ & 92.9 & 101,120 & 120 \\
\hline$+\mathrm{U} 74389 \mathrm{~F}, 10 \mu \mathrm{M}$ & 85.4 & 70,400 & 68 \\
\hline$+\mathrm{U} 74389 \mathrm{~F}, 100 \mu \mathrm{M}$ & 79.3 & 24,320 & 9 \\
\hline LPS & 95.6 & 8640 & 20 \\
\hline$+\mathrm{U} 74389 \mathrm{~F}, 10 \mu \mathrm{M}$ & 90.0 & 4960 & $<5$ \\
\hline$+\mathrm{U} 74389 \mathrm{~F}, 100 \mu \mathrm{M}$ & 84.5 & 2050 & $<5$ \\
\hline Interferon- $\gamma+T N F-c x$ & 94.6 & 1650 & ND \\
\hline$+\mathrm{U} 74389 \mathrm{~F}, 100 \mu \mathrm{M}$ & 78.2 & 260 & ND \\
\hline
\end{tabular}

NOTE. $\mathrm{NO}_{2}^{-}=$nitrite; veh $=$vehicle of U74389F; HKP $=$heat-killed pneumococci $\left(10^{7} \mathrm{cfu} / \mathrm{mL}\right) ; \mathrm{LPS}=$ Escherichia coli lipopolysaccharide; ND $=$ not done

* Detection limit of TNF- $\alpha$ assay was $5 \mathrm{U} / \mathrm{mL}$.

had no effect on CSF pleocytosis $(7240 \pm 700$ vs. $6710 \pm 729$ cells $/ \mu \mathrm{L}), \mathrm{rCBF}(189.3 \% \pm 13.3 \%$ vs. $211.6 \% \pm 5.2 \%)$, or brain water content $(79.04 \% \pm 0.03 \%$ vs. $79.09 \% \pm 0.03 \%)$.

Administration of L-NA $4 \mathrm{~h}$ after infection in U74389F-pretreated rats (group 6) produced an increase in MABP from $98 \pm$ 4 to $124 \pm 5 \mathrm{~mm} \mathrm{Hg}$. The rCBF increase at $4 \mathrm{~h}$ after infection (149.1\% $\pm 14.4 \%$ for group 6 vs. $151.8 \% \pm 7.0 \%$ for group 2$)$ was completely reversed by L-NA $(97.4 \% \pm 12.8 \%$ for group 6 vs. $167.7 \% \pm 3.4 \%$ for group $25 \mathrm{~h}$ after infection).

Inhibition of release of $N O, I L-6$, and $T N F-\alpha$ by peritoneal macrophages stimulated with HKP, E. coli LPS, and cytokines. HKP (in a dose-dependent fashion, data shown only for $10^{7}$ $\mathrm{cfu} / \mathrm{mL}$ ), E. coli LPS, and murine rIFN- $\gamma$ plus murine rTNF$\alpha$ stimulated production of NO, IL-6, and TNF- $\alpha$ in the macrophage cultures (table 2). U74389F inhibited dose dependently NO, IL-6, and TNF- $\alpha$ production by macrophages stimulated with HKP, $E$. coli LPS, or murine rIFN- $\gamma$ plus murine rTNF$\alpha$. HKP $\left(10^{7} \mathrm{cfu} / \mathrm{mL}\right)$-induced production of NO, IL-6, and TNF- $\alpha$ by macrophages was inhibited by U74389F (100 $\mu M)$ by $92 \%, 89 \%$, and $67 \%$, respectively.

Inhibition of lipid peroxidation by U74389F in primary astrocytes. Iron-dependent lipid peroxidation in primary rat astrocyte cultures was inhibited by U74389F and methylprednisolone (figure 2).

\section{Discussion}

The major finding of this study was that pretreatment with the novel 21 -aminosteroid $\mathrm{U} 74389 \mathrm{~F}$ significantly attenuated increases in brain water content and ICP and CSF leukocytosis during the early phase of experimental pneumococcal meningitis in the rat. U74389F had no effect on the increase in $\mathrm{rCBF}$. Administration of U74389F to animals with established meningitis significantly attenuated the increase in ICP but had no effect on CSF pleocytosis or increases in $\mathrm{rCBF}$ and brain water content. The antiedematous effect of U74389F when given prior to infection corresponds with findings in other pathophysiologic CNS models that documented a protective effect of 21 aminosteroids on brain edema formation [19]. The increase in ICP in the early phase of experimental pneumococcal meningitis is thought to be mainly due to an increase in brain water content and an increase in cerebral blood volume [20]. Our finding that the increase in ICP was reduced but not completely

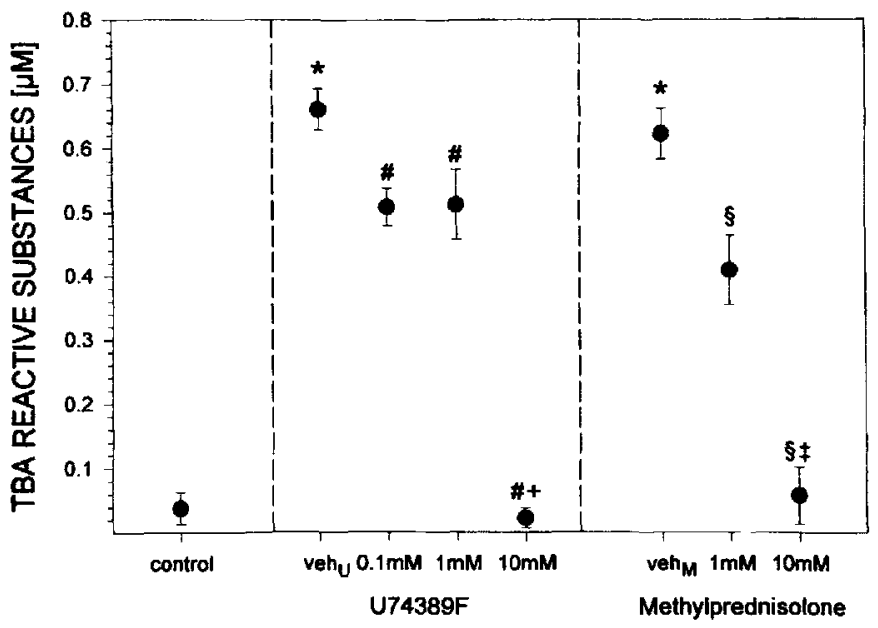

Figure 2. Inhibition of iron-dependent lipid peroxidation in primary rat astrocytes. Lipid peroxidation was assessed by formation of thiobarbituric acid (TBA)-reactive substances (mean $\pm 99 \%$ confidence interval). Addition of $\mathrm{Fe}^{2+} / \mathrm{Fe}^{3+}\left(+\right.$ vehicle of $\mathrm{U} 74389 \mathrm{~F}\left[\mathrm{Veh}_{\mathrm{U}}\right]$ or methylprednisolone $\left[\mathrm{veh}_{\mathrm{M}}\right]$ ) to astrocytes induced significant increase of TBA-reactive substances vs. action of diluent of $\mathrm{Fe}^{2+} / \mathrm{Fe}^{3+}$ (control; $* P<.05$ ). Increase was significantly attenuated by methylprednisolone, known inhibitor of lipid peroxidation ( $₫ \ddagger, P<.05$ vs. veh $_{M}$ and $1 \mathrm{~m} M$, respectively). U74389F also blocked increase of

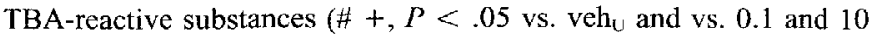
$\mathrm{m} M$, respectively. All $P$ values determined by analysis of variance and Student-Ncwman-Keuls multiple comparisons. 
inhibited might be explained by the lack of influence of U74389F on an increase in $\mathrm{rCBF}$, which, in turn, may be caused at least in part by an increase in cerebral blood volume.

The 21-aminosteroids exhibit protective effects in a variety of pathologic conditions, including cerebral ischemia [21], subarachnoid hemorrhage [22], traumatic brain injury [23], vasogenic edema [19], and endotoxemia [24]. Their protective cffects have been primarily attributed to their capacity to inhibit membrane lipid peroxidation $[12,25]$. We investigated whether $\mathrm{U} 74389 \mathrm{~F}$ is capable of inhibiting iron-dependent lipid peroxidation in a CNS cell culture system. Our in vitro experiments used primary rat astrocytes and showed that the ability of U74389F to suppress lipid peroxidation is comparable to that of methylprednisolone, a potent inhibitor of lipid peroxidation. By inhibiting lipid peroxidation, the 21 -aminosteroids may indirectly exert further inhibitory actions. For example, inhibition of 5-lipoxygenase may prevent the formation of leukotrienes [19], inhibition of NADPH oxidase may prevent the generation of superoxide radical and hydrogen peroxide [26], and inhibition of the destruction of cell membranes may prevent the release of arachidonic acid [27]. Recently, others have suggested that some 21-aminosteroids (e.g., U74389F, U78518F) may have an oxygen radical scavenging effect $[28,29]$.

We tested whether U74389F, apart from inhibiting lipid peroxidation, also interferes with other mediators (e.g., cytokines and NO) known to be involved in the pathophysiology of bacterial meningitis [4, 30, 31]. Peritoneal macrophages, which we used in our in vitro experiments, are an established cell culture system for the induction of cytokines and NO. There are similarities between rat peritoneal macrophages and brain macrophages and microglia: Both cell types produce cytokines [32, $33]$ and NO [34, 35] upon stimulation with LPS and Staphylococcus aureus. Our data provide evidence that the activity of $\mathrm{U} 74389 \mathrm{~F}$ is not restricted to inhibition of lipid peroxidation. U74389F inhibited the production of NO, IL-6, and TNF- $\alpha$ by rat peritoneal macrophages stimulated with heat-killed pneumococci, E. coli LPS, and cytokines. A previous study showed that another 21-aminosteroid compound (U74500A) interferes with the production of cytokines [36]. Our in vitro studies showed that U74389F inhibited NO production by rat peritoneal macrophages; however, in vivo, U74389F (in two different dosages) surprisingly had no effect on blood flow changes, which are known to be NO-mediated [30, 31]. Thus, in our meningitis model, U74389F did not affect NO production, although the addition of the $\mathrm{NO}$ synthase inhibitor $\mathrm{L}-\mathrm{NA}$ reversed the blood flow increase.

We found that $\mathrm{U} 74389 \mathrm{~F}$ reduced meningeal inflammation. This observation is consistent with a recent study in which the 21 -aminosteroid tirilazad mesylate attenuated the accumulation of neutrophils in ischemic gerbil brain [37]. In contrast, others have reported that $\mathrm{U} 74389 \mathrm{~F}$ does not inhibit the hyperoxiainduced accumulation of neutrophils in bronchoalveolar lavage fluid [38]. One explanation for the effect observed in our study may be that 21 -aminosteroids inhibit the generation of superox- ide radical and thereby reduce the expression of adhesive glycoproteins $[39,40]$ and the adherence of neutrophils. Another explanation might be that damage of biomembranes by lipid peroxidation could lead to the release of chemoattractant substances, such as arachidonic acid metabolites or platelet-activating factor, which could be prevented by inhibitors of lipid peroxidation.

Reactive oxygen species are known to play a role in early pathophysiologic changes during experimental bacterial meningitis $[6-10]$. Along with the data from our previous experiments, the results of the current study suggest that lipid peroxidation induced by oxygen free radicals is involved in the pathophysiologic mechanisms during the early phase of pneumococcal meningitis. However, other activities of the 21aminosteroid $\mathrm{U} 74389 \mathrm{~F}$, such as interference with cytokine production, might contribute to the modulation of the pathophysiologic changes in early experimental pneumococcal meningitis.

\section{Acknowledgments}

We thank G. Ruckdeschel (Max-von-Pettenkofer Institute, University of Munich) for pneumococci, Dagmar Förth and Judy Benson for help with manuscript preparation, Alex Heng for excellent assistance with the experiments, and Peter Dirschedl (Institute for Medical Informatics, Biometrie and Epidemiology, University of Munich) for statistical help.

\section{References}

1. Scheld WM, Dacey RG Jr, Winn HR, Welsh JE, Jane JA, Sande MA. Cerebrospinal fluid outflow resistance in rabbits with experimental meningitis. Alterations with penicillin and methylprednisolone. J Clin Invest $1980 ; 66: 243-53$.

2. Täuber MG, Borschberg U, Sande MA. Influence of granulocytes on brain edema, intracranial pressure, and cerebrospinal fluid concentrations of lactate and protein in experimental meningitis. I Infect Dis 1988; $157: 456-64$.

3. Tuomanen EI, Saukkonen K, Sande S, Cioffe C', Wright SD. Reduction of inflammation, tissue damage, and mortality in bacterial meningitis in rabbits treated with monoclonal antibodies against adhesion-promoting receptors of leucocytes. J Exp Med 1989; $170: 959$-69.

4. Mustafa M, Ramilo O, Olsen KD, et al. Tumor necrosis factor in mediating experimental Haemophilus influenzae type b meningitis. J Clin Invest $1989 ; 84: 1253-9$.

5. Smith AL. Pathogenesis of Haemophilus infuenzae type b meningitis. In: Keusch G, Wadström T, eds. Experimental bacterial and parasitic infections. New York: Elsevier, 1983:295-301.

6. Pfister HW, Koedel U, Haberl RL, et al. Microvascular changes during the early phase of pneumococcal meningitis in the rat. J Cereb Blood Flow Metab 1990; 10:914-22.

7. Pfister HW, Koedel U, Dirnagl U, Haberl RL, Ruckdeschel G, Einhäupl KM. Effect of catalase on regional cerebral blood flow and brain edema during the early phase of experimental pneumococcal meningitis. J Infect Dis 1992; 166:1442-5.

8. Pfister HW, Koedel U, Lorenzl S, Tomasz A. Antioxidants attenuate microvascular changes in the early phase of experimental pneumococcal meningitis in rats. Stroke $1992 ; 23: 1798-804$.

9. McKnight AA, Keyes WG, Hudak ML, Jones MD. Oxygen frec radicals and the cerebral arteriolar response to group B streptococci. Pediatr Res $1992 ; 31: 640 \cdots 4$. 
10. Berkowitz ID, Traystman RJ. Oxygen radical scavengers prevent impairment of microvascular autoregulation in $H$. influenzae type $\mathrm{B}$ meningitis in rats [abstract]. Faseb $\mathbf{J}$ 1993; 7:A530.

11. Halliwell $B$. Reactive oxygen species and the central nervous system. I Neurochem 1992;59:1609-23.

12. Haghighi SS, Hall ED, Geng XZ, Oro JJ, Johnson GC. Therapeutic value of 21 -aminostcroid $\mathrm{U} 74389 \mathrm{~F}$ in acute spinal cord injury. Neurol Res 1993; 15:321-6.

13. Bernstein M, Ginsberg H, Glen J. Protection of iodine- 125 brachytherapy brain injury in the rat with the 21 -aminosteroid U-74389F. Neurosurgery 1992;31:923-8.

14. Braughler JM, Duncan LA, Chase RL. The involvement of iron in lipid peroxidation: importance of ferric 10 ferrous ratios in initiation. $J$ Biol Chem 1986; 261:10282-9.

15. Michler-Stuke A, Wolff J, Bottenstein J. Factors influencing astrocyte growth and development in defined media. Int $\mathrm{J}$ Dev Neurosci 1984;2:575--84

16. Frei $K$, Leist TP, Meager A, et al. Production of B cell stimulatory factor2 and interferon gamma in the central nervous system during viral meningitis and encephalitis. Evaluation in a murine model infection and in patients. J Exp Med 1988; 168:449-53.

17. Frei K, Siepl C, Groscurth P, Bodmer S, Schwerdel C, Fontana A. Antigen presentation and tumor cytotoxicity by interferon-gamma-treated microglial cells. Eur J Immunol 1987; 17:1271-8.

18. Stuehr DJ, Marletta MA. Mammalian nitrate biosynthesis: mouse macrophages produce nitrite and nitrate in response to Escherichia coli lipopolysaccharide. Proc Natl Acad Sci USA 1985;82:7738-42.

19. Hall ED, Travis MA. Inhibition of arachidonic acid-induced vasogenic brain edema by the non-glucocorticoid 21 -aminosteroid U74006F. Brain Res 1988; 451:350-2.

20. Tureen JH, Dworkin RJ, Kennedy SL, Sachdeva M, Sande MA. Loss of cerebrovascular autoregulation in experimental meningitis in rabbits. $\mathrm{J}$ Clin Invest 1990; $85: 577-81$.

21. Young W, Wojak JC, DeCrescito V. 21-aminosteroid reduces ion shifts and edema in the rat middle cerebral artery occhusion model of regional ischemia. Stroke 1988; 19:1013-9.

22. Zuccarello M, Anderson DK. Protective effect of a 21 -aminosteroid on the blood-brain barrier following subarachnoid hemorrhage in rats. Stroke 1989;20:367-71.

23. Hall ED, Yonkers PA, McCall JM, Braughler JM. Effects of the 21aminosteroid $\mathrm{U} 74006 \mathrm{~F}$ on experimental head injury in mice. $J$ Neurosurg 1988; 68:456-61.

24. Siegfried MR, Ma X, Lefer AM. Splanchnic vascular endothelial dysfunction in rat endotoxemia: role of superoxide radicals. Eur J Pharmacol 1992; $212: 171-6$.

25. Horton JW, Walker PB. Oxygen radicals, lipid peroxidation, and permeability changes after intestinal ischemia and reperfusion. J Appl Physiol 1993; 74:1515-20.
26. Thomas PD, Mao GD, Rabinovitch A, Poznansky MJ. Inhibition of superoxide-generating NADPH oxidase of human neutrophils by lazaroids (21-aminosteroids and 2-methylaminochromans). Biochem Pharmacol $1993 ; 45: 241-51$.

27. Braughler JM, Chase RL, Neff GL, et al. New 21 -aminosteroid antioxidant lacking glucocorticoid activity stimulates adrenocorticotropin secretion and blocks arachidonic acid relcase from mouse pituitary tumor (AtT20) cells. J Pharmacol Exp Ther 1988;244:423-7.

28. Barnard ML, Gurdian S, Turrens JF. Activated polymorphonuclear leukocytes increase low-level chemiluminescence of isolated perfused rat lungs. J Appl Physiol 1993: 75:933-9.

29. Tanigaki T, Suzuki Y, Heimer D, Sussman HH, Ross WG, Raffin TA. Attenuation of acute lung injury and oxygen radical production by the 21 -aminosteroid, U-78518F. J Appl Physiol 1993;74:2155-60.

30. Pfister HW, Koedel U, Bernatowicz A. Frei K, Fontana A. Role of reactive nitrogen intermediates in experimental pneumococcal meningitis [abstract 796]. In: Program and abstracts of the 33rd Interscience Conference on Antimicrobial Agents and Chemotherapy (New Orleans). Washington, DC: American Society for Microbiology, 1993.

31. Haberl RL, Anneser F, Ködel U, Pfister HW. Is nitric oxide involved as a mediator of cerebrovascular changes in the early phase of experimental pneumococcal meningitis? Neurol Res 1994;16:108-12.

32. Giulian D, Baker TJ, Shih LN, Lachman LB. Interleukin 1 of the central nervous system is produced by ameboid microglia. J Exp Med 1986; 164:594-604.

33. Chung IY, Norris JG, Benveniste EN. Differential tumor necrosis factor- $\alpha$ expression by astrocytes from experimental allergic encephalomyelitissusceptible and -resistant rat strains. J Exp Med 1991; 173:801-11.

34. Merrill JE, Ignarro LJ, Sherman MP, Melinek J, Lane TE. Microglial cell cytotoxicity of oligodendrocytes is mediated through nitric oxide. J Immunol 1993; 151:2132-41.

35. Bosca L, Lazo PA. Induction of nitric oxide release by MRC OX-44 (antiCD53) through a protein kinase $\mathrm{C}-$ dependent pathway in rat macrophages. J Exp Med 1994; 179:1119-26.

36. Fisher M, Plante GM, Doyle EM. Inhibition of inflammatory cell-mediated myelin oxidation and interleukin 1-beta generation by a 21 -aminosteroid, U74500A. J Neurol Sci 1993;119:189-94.

37. Williams LR, Oostveen JA. Tirilazad mesylate attenuates the accumulation of neutrophils in ischemic brain. Ann NY Acad Sci 1993;679:330-4.

38. Richards IM, Griffin RL, Fidler SF, Jacobsen EJ. Effect of the 21 -aminosteroid, U-74389F, on hyperoxic lung injury in rats. Agents Actions 1993; 39:C136-8.

39. Suzuki M, Grisham MB, Granger DN. Leukocyte-endothelial cell adhesive interactions: role of xanthine oxidase derived oxidants. J Leukoc Biol 1991; 50:488-94.

40. Patel KD, Zimmerman GA, Prescott SM, McEver RP, McIntyre TM. Oxygen radicals induce human endothelial cells to express GMP- 140 and bind neutrophils. J Cell Biol 1991; 112:749-59. 